\title{
Migrant youth's emerging dietary patterns in Haiti: the role of peer social engagement
}

\author{
Jessica Heckert ${ }^{1, *}$, Sandra Boatemaa ${ }^{2}$ and Claire E Altman ${ }^{3}$ \\ 'Poverty, Health, and Nutrition Division, The International Food Policy Research Institute, $2033 \mathrm{~K}$ Street NW, \\ Washington, DC 20006, USA: ${ }^{2}$ Regional Institute for Population Studies, The University of Ghana, Legon, Accra, \\ Ghana: ${ }^{3}$ Department of Sociology, Rice University, Houston, TX, USA
}

Submitted 16 June 2013: Final revision received 14 May 2014: Accepted 6 June 2014: First published online 28 July 2014

\begin{abstract}
Objective: The present study examines whether rural-to-urban migrant youth consume a greater diversity of high-sugar beverages and fried snacks (HSBFS) compared with their peers who remain in rural areas. It also tests whether the association between migration and HSBFS diversity is moderated by migrant youth's social engagement with their peers.

Design: Participants were recruited in August and September 2011 following the completion of primary school (6th grade) and shortly before many rural youth migrate to urban areas. Participants were re-interviewed six months later. HSBFS diversity was assessed at follow-up; analyses control for baseline and follow-up characteristics.

Setting: Baseline interviews occurred in rural Southeast Haiti. Follow-up interviews of migrants occurred at urban destinations in Haiti.

Subjects : The sample includes 215 youth (mean age 15.9 years; $43.3 \%$ female; $21.9 \%$ rural-to-urban migrants) who were interviewed at baseline and follow-up. Results: Rural-to-urban migrant youth consumed a greater diversity of HSBFS products at follow-up than their rural counterparts $(b=0 \cdot 70, P \leq 0 \cdot 05)$. Moreover, we found that this relationship varied by level of peer social engagement. Youth who migrated and had a high degree of peer social engagement consumed $2 \cdot 2$ additional types of HSBFS products daily than their counterparts who remained in rural areas and had low peer social engagement.

Conclusions: Higher HSBFS diversity among migrant youth is consistent with the patterns proposed by the nutrition transition. Interactions with peers may have an important influence as migrant youth adopt new dietary preferences. Emerging dietary patterns among youth migrants have important implications for health trajectories and the development of degenerative diseases.
\end{abstract}

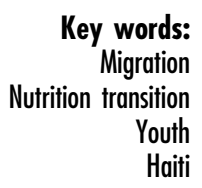

Urbanization - one of several factors associated with the adoption of diets high in fat and refined sugar ${ }^{(1)}$ and sedentary behaviours ${ }^{(2)}$ - underpins the obesity epidemic in Latin America and the Caribbean. This pattern characterizes the fourth stage of the nutrition transition, whereby increasingly urban populations consume diets high in fat, sugar and processed foods ${ }^{(3)}$. These lifestyle factors drive higher morbidity and mortality from degenerative diseases $^{(4)}$. Migration from rural areas to cities - the largest contributor to urbanization within the Global South $\dagger^{(5)}-$ provides a context for examining emerging dietary patterns associated with urbanization. Urban Haiti, like many cities

$\dagger$ 'Global South' refers to the countries of Latin America, Africa and most parts of Asia. in the Global South, has experienced a rise in obesity and associated non-communicable chronic diseases, including hypertension and diabetes. Although the obesity prevalence in Haiti is low relative to other Latin American and Caribbean countries, the national prevalence among women aged 15 to 49 years has more than doubled from $2.6 \%$ in $1994-1995$, to $6 \cdot 3 \%$ in $2005-2006$ and $7 \cdot 8 \%$ in $2012^{(6-8)}$. In 2006 among the adult population of Port-au-Prince, $48.7 \%$ of men and $46.5 \%$ of women were hypertensive, and the age-standardized prevalence of glucose intolerance was $11.2 \%$ among men and $16.9 \%$ among women, higher than the average among urban Latin American and Caribbean inhabitants ${ }^{(9)}$. These changes occur even as underweight and stunting in the country's rural areas remain primary concerns $^{(10)}$. 
Rural-to-urban migrants encounter new built and social environments and labour arrangements that may alter diets and activity levels ${ }^{(2,11,12)}$. In urban food environments, sugary, fatty, pre-packaged and processed foods are available in greater variety and closer proximity ${ }^{(3,13,14)}$. Although Haiti itself has low manufacturing capacity, processed foods are imported ${ }^{(15)}$, and declining tariffs between the USA and the Caribbean have increased the availability of highly processed foods and further fuelled the nutrition transition ${ }^{(16)}$. Furthermore, new urbanites come to rely on purchased foods (rather than agriculture) $)^{(11)}$ and favour convenient products as employment opportunities pull primary food preparers from the home ${ }^{(17,18)}$.

Research examining dietary behaviours among adult migrants in the Global South concludes that rural-to-urban migrants have diets higher in fat from oils and animal-source foods, sugar and sweeteners, and energy, which contributes to rising obesity and cardiovascular health conditions ${ }^{(19-22)}$. Rural-to-urban adult migrants in India consume Western foods (sweetened, processed and energy-dense foods and beverages) more frequently than non-migrant family members ${ }^{(23)}$. In Guatemala both sweetened beverages and red meat were consumed more frequently among rural-to-urban migrants ${ }^{(24)}$. However, no such study examines related outcomes among younger migrants, even though youth those aged 12 to 24 years* - compose a substantial proportion of migrants ${ }^{(25)}$. In Haiti, more than half the youth population has migrated at least once and rural-to-urban migration is the primary pattern ${ }^{(26,27)}$. Focusing on youth's dietary behaviours as they adapt to an urban context is merited, because early life course health has a cumulative impact on degenerative disease development ${ }^{(28,29)}$. Moreover, dietary behaviours, when acquired young, are difficult to modify ${ }^{(30)}$.

Youth migrants encounter greater food variety and a new social context in urban destinations at a time when exposure to novel experiences may alter their behaviours ${ }^{(31)}$. Youth experience rapid physical, social and psychological development, and the amount of time spent with peers and peers' relative importance increase ${ }^{(31)}$. Migrant youth's new peer groups in urban areas may transmit dietary ideals and practices, and social engagement with peers generates exposure to these ideals and practices. Among Haitian adolescents, food and beverages are commonly shared to build and reinforce social alliances ${ }^{(32)}$, and youth migrants may seek cues about how to act from urban peers as a way of integrating into their new environment and attaining status. Peers may also convey ideals about food choice and encourage particular products, which may be experienced as peer pressure among new migrant youth ${ }^{(33)}$.

Building on previous literature, we aim to examine how migration facilitates the consumption of high-sugar beverages

\footnotetext{
* The UN and the WHO define youth as those aged 12 to 24 years, but often operationalize the lower end of the range as either 10 or 15 years to align with data availability.
}

and fried snacks (HSBFS) among rural-to-urban youth migrants. We focus specifically on differences in the diversity of HSBFS products consumed - one mechanism that may influence youth's eating behaviours and promote increased consumption $^{(34)}$. To our knowledge, no study to date specifically examines the diversity of HSBFS consumption among youth migrants; therefore, we first assess this association. Based on previous findings among rural-to-urban adult migrants $^{(21,23,35)}$, we hypothesize that migrant youth will consume a greater diversity of HSBFS products. We further test whether consuming a greater diversity of HSBFS products among migrant youth is conditional on having high peer social engagement. We hypothesize that joint exposure to an urban environment - where HSBFS products are more readily available - and a high level of social interaction with peers - who may encourage consumption of HSBFS - will account for the diversity of HSBFS products consumed.

\section{Methods}

\section{Design and participants}

These data were collected as part of the Haitian Youth Transitions Study (HYTS). The study recruited a cohort of youth who had recently completed primary school (6th grade) in the rural section of a commune (local administrative unit) in Southeast Haiti. Primary-school directors provided lists of students who completed their 6th grade exams in the summer of 2011; all students were invited to participate. Recruitment, youth baseline interviews and parent or guardian interviews occurred in August and September 2011. Follow-up interviews occurred in February and March 2012, after approximately one-fifth (21.9\%) of participants had migrated to an urban area.

Interviews lasted approximately an hour and participants were interviewed in Haitian Creole, their native language, by trained interviewers. Questions were posed orally and interviewers recorded responses. The interview began with a life-history calendar to record migration information and develop rapport between the interviewer and participant; it then included questions on health behaviours and social context. Ethnographic fieldwork and semi-structured interviews conducted prior to and during the survey period informed its design, content and question wording; in the discussion we inform our quantitative findings with these qualitative data. The present study analyses data from the 215 youth (90\% of those eligible) who were interviewed at follow-up in February and March 2012 when HSBFS diversity was measured.

The study was conducted according to the guidelines of the Declaration of Helsinki and all procedures involving human subjects were approved by the Institutional Review Board of the Pennsylvania State University. Additionally, a local organization dedicated to the preservation of human rights and the commune's local government approved the research. Verbal informed consent was obtained from 
participants aged 18 years and older. For participants younger than 18 years, their verbal assent and the verbal consent of a parent or guardian were obtained. These were witnessed and recorded before the interview began.

\section{Measures}

Table 1 includes the question wording and variable coding. At follow-up, to measure the diversity of HSBFS products consumed, participants were asked to recall the previous day's food consumption based on a list of common food products accessible to both urban and rural youth. The list contained six HSBFS products, including sweetened fresh juice, bottled juice, soda, sport shake, pre-packaged fried snacks (e.g. chips, cheese puffs) and fried street food. Consumption of each item on the previous day was a binary variable. The six HSBFS product categories were summed ( $\alpha=0 \cdot 69$; range $0-6)$.

Youth were identified as migrants based on their lifehistory calendar, which was completed at baseline and augmented at follow-up to reflect changes that had occurred since baseline.

Peer social engagement was binary; at follow-up it combined responses to questions on organized and nonorganized social activities. Youth who participated in organized youth activities (e.g. church youth groups, community improvement groups, dance performance) during the past three months received a score of 1 . Regarding non-organized social activities, youth were asked how they spent time with peers of the same sex and opposite sex. Interviewers recorded up to two responses for each of these open-ended questions; we classified these responses as either social (e.g. sports, congregating at local gathering spots, informal study groups) or non-social (e.g. chores, no friends, not permitted to go out) and scored responses separately for same-sex and opposite-sex peers. If either reported activity for each question was a social activity, we classified the response as social. We summed values for whether youth participated in: (i) organized social activities; (ii) non-organized social activities with same-sex peers; and (iii) non-organized social activities with opposite-sex peers. Youth with a score of 3 had high peer social engagement.

Peer social engagement at baseline was again binary, but was limited to non-organized social activities, as organized youth activities are less common during school vacations when baseline data were collected. Youth were asked how they spent time with same-sex and oppositesex peers. Non-organized social activities were coded the same for baseline and follow-up, and the values of non-organized social activities with same-sex and opposite-sex peers were summed; those with the maximum score (2) were classified as having high baseline peer social engagement. Because baseline data were collected during summer vacation when youth's social activity patterns differ from the school year, and because the baseline and follow-up peer social engagement variables were constructed differently, the values of high peer social engagement at baseline and follow-up cannot be compared directly with one another. However, the values can compare migrants and non-migrants with one another at baseline and follow-up.

Food security combined responses to two questions adapted from the Household Hunger Scale ${ }^{(36)}$ : 'How often did you eat less?' and 'How often did you go without eating because of insufficient money or food?' Responses were combined into a $Z$-score (baseline $\alpha=0.69$; followup $\alpha=0.71$; range $-2 \cdot 7$ to $2 \cdot 3$ ); higher scores indicate higher food security.

At baseline, a parent or guardian answered questions on durable goods ownership, land ownership, livestock ownership, housing quality and remittance receipt. The responses were combined to form an asset index ( $Z$-scored) using principal components analysis (range $-3 \cdot 5$ to $4 \cdot 6)^{(37)}$. The asset index reflects the overall wealth of the household where the youth lived at baseline. Baseline variables are used, because asset index values are not comparable between rural and urban households ${ }^{(37)}$, and migrant youth's access to resources corresponds closely to their home of origin.

School day refers to whether the reference day for food consumption was a school day. Gender refers to the youth, and youth's age was measured at follow-up.

\section{Analyses}

We first calculated descriptive characteristics (means or percentages) for all variables and used $t$ tests to compare migrants and non-migrants on these characteristics. We then used ordinary least squares regression to examine how each independent variable is associated with diversity of HSBFS consumption at follow-up (unconditional associations).

We then used multivariate ordinary least squares regression to predict the diversity of HSBFS products consumed at follow-up using covariates from both the baseline and follow-up surveys. Model 1 includes only migration and high peer social engagement. Model 2 includes an interaction between migration and social engagement to test whether the association between the diversity of HSBFS consumption and migration varies across high and low peer social engagement. Model 3 builds on Model 2 and controls for follow-up food security (limited to one time point to avoid multicolinearity), baseline peer social engagement, baseline family assets, gender, age and whether the day for which consumption was measured was a school day.*

All analyses were conducted using the statistical software package STATA $12 \cdot 0$ and used multiple imputation procedures to avoid the loss of the eighteen respondents

\footnotetext{
* We did not include the relationship with the head of household in the multivariate model, because including a binary variable that corresponds to greater than $80 \%$ of respondents can lead to misestimated models.
} 
Table 1 Description of variables used in the study

\begin{tabular}{|c|c|c|c|}
\hline Variable & Question & Responses & How coded \\
\hline HSBFS diversity (follow-up) & $\begin{array}{l}\text { I am going to read the name of some products, and I want you to respond yes or } \\
\text { no to whether you consumed it yesterday: sweetened fresh juice, bottled } \\
\text { juice, soda, sport shake, pre-packaged fried snacks (e.g. chips, cheese } \\
\text { puffs), fried street food }\end{array}$ & $\begin{array}{l}\text { Yes }=1 / \text { no }=0 \text { for each of the six } \\
\text { categories }\end{array}$ & Values range from 0 to 6 \\
\hline $\begin{array}{l}\text { Migrant (between baseline } \\
\text { and follow-up) }\end{array}$ & $\begin{array}{l}\text { Where do you live currently? Are there any other places where you lived since } \\
\text { we last spoke in August? When did you live in each of these places? }\end{array}$ & $\begin{array}{l}\text { Information was recorded on a life-history } \\
\text { calendar }\end{array}$ & Migration to urban area $=1$ \\
\hline \multirow[t]{3}{*}{$\begin{array}{l}\text { High peer social } \\
\text { engagement (follow-up) }\end{array}$} & $\begin{array}{l}\text { When you are not at school or at home, what two places do you spend the most } \\
\text { time with youth who are the same gender as you? }\end{array}$ & $\begin{array}{l}\text { Open responses; social activities }=1 \\
\text { (e.g. sports, congregating at local } \\
\text { gathering spots, informal study } \\
\text { groups); non-social activities }=0 \text { (e.g. } \\
\text { chores, no friends, not permitted to go } \\
\text { out) }\end{array}$ & \multirow[t]{3}{*}{$\begin{array}{l}\text { High peer social } \\
\text { engagement }=1 \text { if the sum } \\
\text { of all three questions }=3\end{array}$} \\
\hline & $\begin{array}{l}\text { When you are not at school or at home, what two places do you spend the most } \\
\text { time with youth who are not the same gender as you? }\end{array}$ & $\begin{array}{l}\text { Open responses; social activities }=1 \\
\text { non-social activities }=0\end{array}$ & \\
\hline & $\begin{array}{l}\text { During the last three months, did you participate in an organized group with } \\
\text { other youth? (e.g. church youth groups, community improvement groups, } \\
\text { dance performance) }\end{array}$ & Yes $=1 / \mathrm{no}=0$ & \\
\hline \multirow[t]{2}{*}{$\begin{array}{l}\text { High peer social } \\
\text { engagement (baseline) }\end{array}$} & $\begin{array}{l}\text { When you are not at school or at home, what two places do you spend the most } \\
\text { time with youth who are the same gender as you? }\end{array}$ & $\begin{array}{l}\text { Open responses; social activities }=1 \\
\text { non-social activities }=0\end{array}$ & \multirow{2}{*}{$\begin{array}{l}\text { High peer social } \\
\text { engagement }=1 \text { if the sum } \\
\text { of both questions }=2\end{array}$} \\
\hline & $\begin{array}{l}\text { When you are not at school or at home, what two places do you spend the most } \\
\text { time with youth who are not the same gender as you? }\end{array}$ & $\begin{array}{l}\text { Open responses; social activities }=1 \\
\text { non-social activities }=0\end{array}$ & \\
\hline $\begin{array}{l}\text { Food security (baseline } \\
\text { and follow-up) }\end{array}$ & $\begin{array}{l}\text { During the past month, how many days did you have to eat less because there } \\
\text { was not enough money or food? } \\
\text { During the past month, how many days did you have to go the whole day } \\
\text { without eating because there was not enough money or food? }\end{array}$ & $\begin{array}{l}\text { (i) Never, (ii) once, (iii) several days, but } \\
\text { less than } 15 \text {, (iv) more than } 15 \text { days, } \\
\text { (v) every day or nearly every day }\end{array}$ & $\begin{array}{l}\text { Responses combined to form } \\
Z \text {-score }(-2 \cdot 7 \text { to } 2 \cdot 3) \text {; higher } \\
\text { values are more food secure }\end{array}$ \\
\hline \multirow[t]{5}{*}{ Family assets (baseline) } & Do you own a $<$ bicycle/motorcycle/watch/cell phone/generator/solar panels $>$ ? & Yes $=1 / \mathrm{no}=0$ & \multirow{5}{*}{$\begin{array}{l}\text { Responses combined to form } \\
\text { a Z-score (-3.5 to } 4.6) \text { using } \\
\text { principal components } \\
\text { analysis; higher values are } \\
\text { wealthier households }\end{array}$} \\
\hline & $\begin{array}{l}\text { Do you own }<\text { the land where house is built/land for agriculture }>\text { ? } \\
\text { How many }<\text { chickens/cows/goats/pigs/work animals }>\text { do you own? }\end{array}$ & $\begin{array}{l}\text { Yes }=1 / \text { no }=0 \\
\text { Number of animals }\end{array}$ & \\
\hline & What type of $<\mathrm{roof} /$ walls/flooring/toilet $>$ do you have? & & \\
\hline & & $\begin{array}{l}\text { thatched }=0 \text {; floor: } \text { cement }=1 \text {, dirt }=0 \text {; } \\
\text { toilet: enclosed latrine }=1 \text {, open or } \\
\text { none }=0\end{array}$ & \\
\hline & $\begin{array}{l}\text { Does your household receive remittances from others living outside the } \\
\text { household? }\end{array}$ & Yes $=1 / \mathrm{no}=0$ & \\
\hline $\begin{array}{l}\text { Reference day is a school } \\
\text { day }\end{array}$ & $\begin{array}{l}\text { Date of interview was recorded by interviewer and school days were recorded in } \\
\text { field notes }\end{array}$ & & School day $=1$ \\
\hline Age & How old were you on your last birthday? & & Years \\
\hline Gender & Determined by interviewer & Male/female & Male $=1$ \\
\hline Child of head of household & How are you related to the head of the household? & & Child of head $=1$ \\
\hline
\end{tabular}

HSBFS, high-sugar beverages and fried snacks. 
Table 2 Characteristics of respondents in the Haitian Youth Transition Study

\begin{tabular}{|c|c|c|c|c|c|c|c|}
\hline & \multicolumn{2}{|c|}{$\begin{array}{l}\text { Complete sample } \\
\qquad(n 215)\end{array}$} & \multicolumn{2}{|c|}{$\begin{array}{l}\text { Migrants } \\
(n \text { 47) }\end{array}$} & \multicolumn{2}{|c|}{$\begin{array}{l}\text { Non-migrants } \\
\quad(n \text { 168) }\end{array}$} & \multirow{2}{*}{$\begin{array}{c}\text { Migrants } v \text {. } \\
\text { non-migrants, } t \text { tes } \\
P\end{array}$} \\
\hline & $\%$ or Mean & SE & $\%$ or Mean & SE & $\%$ or Mean & SE & \\
\hline \multicolumn{8}{|l|}{ Baseline characteristics } \\
\hline High peer social engagement† (\%) & 68.3 & - & $59 \cdot 2$ & - & $70 \cdot 8$ & - & \\
\hline Family assets (Z-score) & 0.0 & 0.08 & 0.4 & 0.20 & -0.1 & 0.08 & * \\
\hline Food security (Z-score) & 0.0 & 0.07 & 0.4 & 0.14 & -0.1 & 0.07 & ** \\
\hline Age (years) & $15 \cdot 9$ & $0 \cdot 17$ & $15 \cdot 0$ & 0.40 & $16 \cdot 1$ & $0 \cdot 18$ & ** \\
\hline Male (\%) & $56 \cdot 7$ & - & 53.2 & - & 57.7 & - & \\
\hline Child of household head (\%) & $85 \cdot 6$ & - & $80 \cdot 9$ & - & $86 \cdot 9$ & - & \\
\hline \multicolumn{8}{|l|}{ Follow-up characteristics } \\
\hline Migrant $(\%)$ & 21.9 & - & - & - & - & - & \\
\hline HSBFS diversity (no. of product groups) & 2.4 & 0.12 & 3.0 & 0.27 & $2 \cdot 3$ & 0.14 & * \\
\hline High peer social engagement† (\%) & $45 \cdot 1$ & - & $24 \cdot 3$ & - & $51 \cdot 0$ & - & 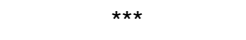 \\
\hline Food security (Z-score) & 0.0 & 0.06 & 0.4 & 0.13 & -0.1 & 0.07 & 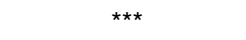 \\
\hline Intake day is a school day (\%) & $54 \cdot 0$ & - & $31 \cdot 9$ & - & $60 \cdot 1$ & - & $* * *$ \\
\hline
\end{tabular}

HSBFS, high-sugar beverages and fried snacks.

${ }^{\star} P<0.05,{ }^{* \star} P<0.01,{ }^{* * \star} P<0.001$.

†High peer social engagement variables are not the same at baseline and follow-up and therefore cannot be compared.

for whom at least one response was missing. In this approach multiple data sets (ten in this case) were generated in which missing values were replaced with plausible ones using imputation by chained equations. Using the -mi estimate- prefix, estimates were calculated separately for each data set, and the results were combined. Reported point estimates are the average values across the ten data sets, and standard errors were calculated according to Rubin's rules ${ }^{(38)}$.

\section{Results}

\section{Descriptive and bivariate characteristics}

Table 2 describes the characteristics of respondents in the HYTS; information is reported for the complete sample and separately for migrants and non-migrants. The final column indicates whether values for migrants and nonmigrants differed significantly on these values. At baseline migrant youth came from wealthier $(P \leq 0.05)$ and more food-secure households $(P \leq 0 \cdot 01)$; they were also on average $1 \cdot 1$ years younger than non-migrant youth $(P \leq 0 \cdot 01)$. Migrant and non-migrant youth did not differ significantly at baseline in their levels of peer social engagement, gender or whether they were the child of the household head.

Turning to characteristics at follow-up, $21.9 \%$ of respondents migrated to urban areas, and of these, $77 \%$ migrated to Port-au-Prince. Migrants reported consuming a wider diversity of HSBFS products during the previous day than non-migrant peers who remained in rural areas $(3.0 \mathrm{v} .2 \cdot 3$; $P \leq 0.05)$. Approximately one-quarter of migrants (24.3\%) compared with one-half of non-migrants $(51.0 \%)$ reported high peer social engagement at follow-up $(P \leq 0 \cdot 001)$. Migrants likely engage with peers less frequently because they are still adapting to new social environments. Migrants reported higher food security than non-migrants (0.42 $v$. $-0.11 ; P \leq 0 \cdot 001)$ and fewer migrant youth referenced a school day for food recall $(31.9 \% v .60 \cdot 1 \% ; P \leq 0 \cdot 001)$.

Table 3 describes how each independent variable that would be included in the multivariate models is associated with the diversity of HSBFS products consumed. As was found in Table 2, migration was positively and significantly associated with the consumption of a wider diversity of HSBFS products $(b=0 \cdot 70 ; t=2 \cdot 33, P \leq 0 \cdot 05)$. There was also a marginally significant positive association between high peer social engagement at follow-up and wider diversity of HSBFS consumption $(b=0.48 ; t=1.93 ; P \leq 0 \cdot 1)$. Similarly, baseline peer social engagement was positively associated with increased diversity of HSBFS consumption $(b=0 \cdot 60$; $t=2 \cdot 22 ; P \leq 0 \cdot 05$ ). Food security at follow-up was positively associated with wider diversity of HSBFS consumption ( $b=0.37 ; t=2 \cdot 66, P \leq 0.01)$ and wealthier youth consumed somewhat more HSBFS products $(b=0 \cdot 21 ; t=1 \cdot 71 ; P \leq 0 \cdot 1)$. Gender, school day and age were not significantly associated with diversity of HSBFS consumption.

\section{Multivariate models}

Multivariate models examined if the number of different HSBFS products consumed on the previous day varied by whether youth interacted frequently with their peers and if the findings were robust to control variables. Model 1 (Table 4) included migration and peer social engagement. When included together, the effect for migration was positive and significant $(b=0 \cdot 87, P \leq 0 \cdot 01)$, as was the effect for peer social engagement $(b=0.64, P \leq 0.05)$.*

\footnotetext{
* The increase in the magnitudes of both variables when they are jointly included in the model fulfils the standard definition of positive cooperative suppression, which occurs when the third variable (follow-up peer social engagement) is negatively associated with the primary independent variable (migration), as is the case herein ${ }^{(39)}$. This suggests that - although migrant youth have lower peer social engagement - engagement with peers in the urban environment may further foster HSBFS diversity.
} 
Table 3 Unconditional beta coefficients: ordinary least squares regression predicting the number of HSBFS products consumed on the previous day, Haitian Youth Transition Study

\begin{tabular}{|c|c|c|c|c|c|}
\hline \multirow[b]{2}{*}{ Migrant } & \multirow{2}{*}{$\frac{b}{0.70}$} & \multicolumn{2}{|c|}{$95 \% \mathrm{Cl}$} & \multirow{2}{*}{$\frac{t \text { Test }}{2.33}$} & \multirow{2}{*}{$\frac{P}{*}$} \\
\hline & & 0.11 & 1.30 & & \\
\hline High peer social engagement (follow-up) & 0.48 & -0.01 & 0.97 & 1.93 & $\left({ }^{*}\right)$ \\
\hline High peer social engagement (baseline) & 0.60 & 0.07 & 1.14 & $2 \cdot 22$ & * \\
\hline Food security (follow-up) & 0.37 & $0 \cdot 10$ & 0.65 & 2.66 & ** \\
\hline Family assets (baseline) & 0.21 & -0.03 & 0.45 & 1.71 & $\left({ }^{*}\right)$ \\
\hline Male & 0.01 & -0.48 & 0.51 & 0.06 & \\
\hline Intake day is a school day (follow-up) & 0.08 & -0.41 & 0.58 & 0.33 & \\
\hline Age (baseline) & 0.38 & -0.06 & 0.14 & 0.75 & \\
\hline
\end{tabular}

HSBFS, high-sugar beverages and fried snacks.

$\left({ }^{\star}\right) P<0.10,{ }^{*} P<0.05,{ }^{\star \star} P<0.01,{ }^{\star \star \star} * P<0.001$.

Table 4 Multivariate ordinary least squares regression predicting the number of HSBFS products consumed on the previous day, Haitian Youth Transition Study

\begin{tabular}{|c|c|c|c|c|c|c|c|c|c|c|c|c|}
\hline \multirow[b]{3}{*}{ Migration } & \multicolumn{4}{|c|}{$\begin{array}{l}\text { Model 1: Joint effects } \\
\text { of migration and peer } \\
\text { social engagement }\end{array}$} & \multicolumn{4}{|c|}{$\begin{array}{l}\text { Model 2: Migration } \\
\text { and high peer social } \\
\text { engagement }\end{array}$} & \multicolumn{4}{|c|}{$\begin{array}{l}\text { Model 3: Includes } \\
\text { control interaction variables }\end{array}$} \\
\hline & \multirow{2}{*}{$\frac{b}{0.87}$} & \multicolumn{2}{|c|}{$95 \% \mathrm{Cl}$} & \multirow{2}{*}{$\frac{P}{* *}$} & \multirow{2}{*}{$\frac{b}{0.45}$} & \multicolumn{2}{|c|}{$95 \% \mathrm{Cl}$} & \multirow[t]{2}{*}{$P$} & \multirow{2}{*}{$\frac{b}{0.35}$} & \multicolumn{2}{|c|}{$95 \% \mathrm{Cl}$} & \multirow[t]{2}{*}{$P$} \\
\hline & & 0.27 & 1.48 & & & -0.26 & $1 \cdot 16$ & & & -0.39 & 1.09 & \\
\hline High peer social engagement (follow-up) & 0.64 & 0.15 & 1.14 & * & 0.39 & -0.15 & 0.93 & & 0.39 & -0.18 & 0.95 & \\
\hline $\begin{array}{l}\text { Migration } \times \text { high peer social engagement } \\
\text { (follow-up) }\end{array}$ & & & & & 1.48 & $0 \cdot 15$ & $2 \cdot 81$ & * & 1.44 & $0 \cdot 14$ & $2 \cdot 75$ & * \\
\hline High peer social engagement (baseline) & & & & & & & & & 0.52 & -0.08 & $1 \cdot 11$ & $\left({ }^{*}\right)$ \\
\hline Food security (follow-up) & & & & & & & & & 0.45 & 0.13 & 0.77 & $* *$ \\
\hline Family assets (baseline) & & & & & & & & & 0.13 & -0.11 & 0.36 & \\
\hline Male & & & & & & & & & -0.09 & -0.68 & 0.49 & \\
\hline Intake day is a school day & & & & & & & & & 0.20 & -0.30 & 0.69 & \\
\hline Age & & & & & & & & & 0.07 & -0.03 & 0.17 & \\
\hline Constant & 1.95 & 1.58 & $2 \cdot 32$ & *** & 2.08 & 1.69 & $2 \cdot 46$ & $\star \star \star *$ & 0.57 & $-1 \cdot 11$ & $2 \cdot 25$ & \\
\hline$F$ test & $6.05^{\star \star \star}$ & & & & $5 \cdot 71^{\star \star \star}$ & & & & $3.81^{\star \star \star}$ & & & \\
\hline Degrees of freedom† & 2, 20 & & & & 3,2 & $6 \cdot 2$ & & & 9,20 & & & \\
\hline$R^{2}$ & 0.06 & & & & 0.08 & & & & 0.15 & & & \\
\hline
\end{tabular}

HSBFS, high-sugar beverages and fried snacks.

$\left({ }^{\star}\right) P<0.10,{ }^{\star} P<0.05,{ }^{\star \star} P<0.01,{ }^{\star * \star} P<0.001$.

tDecimal values for the residual degrees of freedom are a result of multiple imputation procedures.

In Model 2, with the migration by high peer social engagement interaction, neither the conditional main effect of migration nor high peer social engagement was significant. However, the interaction term was significant $(b=1.48$, $P \leq 0.05)$. Interpreting these findings in the context of the interaction term, the non-significant effect of peer social engagement indicates that there is no significant effect for peer social engagement among non-migrants. Likewise, the non-significant effect of migration indicates that among those with low peer social engagement, migration is not associated with HSBFS diversity. However, the positive interaction term suggests that the combination of migration and high peer social engagement is associated with consuming 1.5 more HSBFS products on a daily basis. These findings indicate a multiplicative effect; moving to urban areas and being socially engaged with one's peers are jointly associated with increased HSBFS diversity.

In Model 3, we examined if the findings hold after controlling for confounding factors; the migration by high peer social engagement interaction was minimally attenuated. Food security is the only control variable that was significant in the multivariate model $(b=0.45$, $P \leq 0 \cdot 01)$. Baseline peer social engagement was moderately and positively associated with HSBFS diversity. The remaining variables included in the model (family assets, gender, whether recall was for a school day and age) were not significant. We used the estimates from Model 3 to calculate the predicted value of HSBFS diversity for migrants and non-migrants with low and high peer social engagement while holding the other variables constant at their means (Fig. 1).

As a whole, these findings support our hypothesis that joint exposure to both the urban environment and interactions with peers contributes to consuming a wider diversity of HSBFS products. We tested the sensitivity of our finding using alternative specifications of the peer social engagement variable; our findings did not change substantively. 


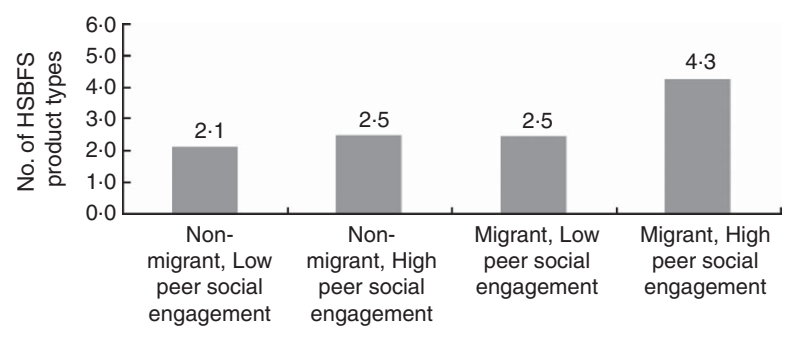

Fig. 1 Predicted values of high-sugar beverages and fried snacks (HSBFS) diversity among rural-to-urban migrant and rural non-migrant youth ( $n$ 215, mean age 15.9 years), Haitian Youth Transitions Study, February-March 2012. Note: calculations from Table 4, Model 3, with all other values constant at mean

\section{Discussion}

Our findings reveal that rural-to-urban migrant youth consume a greater diversity of HSBFS products on a daily basis than their peers who remain in rural areas. Previous studies observe higher intake of sugary, fatty and processed foods among rural-to-urban migrants compared with rural non-migrants ${ }^{(21,23,24,35)}$. Consistent with the nutrition transition, these provide examples of how urban environments contribute to the increased consumption of processed foods ${ }^{(2,4,11)}$. The current findings build on these previous studies and suggest that one mechanism underlying increased intake found in previous studies may be that rural-to-urban migrant youth consume a wider diversity of HSBFS products. Furthermore, because we control for food security and family assets, it is suggestive that migrant youth consume these products in addition to regular meals, not as a replacement for them. This is consistent with a pattern of food consumption in urban environments where these foods are readily accessible, particularly in Port-au-Prince where the availability of these products has expanded in recent decades ${ }^{(15,16,19,40)}$.

Turning to the second component of our study, our findings support the expectation that the association between migration and HSBFS diversity varies by level of peer social engagement. Migrants with high peer social engagement consume, on average, 4.3 products daily and non-migrants with low peer social engagement consume an average of $2 \cdot 1$ products. Moreover, because this finding persists after controlling for peer social engagement at baseline, it is unlikely that the effect of peer social engagement measured at follow-up reflects innate personality characteristics and likely that it reflects the migration-adaptation process.

The findings raise an important question: why is peer social engagement associated with consuming a greater diversity of HSBFS products among migrant youth? We propose two potential explanations. First, young migrants aim to fit in and adapt to their new environments. A wide range of studies from Western countries and the Global South demonstrate the importance of peer influences and peer approval on youth behaviour ${ }^{(41,42)}$. HSBFS consumption may have a strong social component; when purchasing and sharing soda or a bag of chips, youth also forge friendships, as food sharing builds social alliances in Haitian culture ${ }^{(32,33,43)}$. In Haiti, these products are widely sold and consumed in public spaces where youth congregate, such as school yards and social gathering spaces; thus, consuming HSBFS coincides with peer interactions. Food choices, particularly popular snack products, may also result from peer pressure, which has been demonstrated by evidence from Western countries and the Global South $^{(43-45)}$. As a whole, as migrant youth adapt to new urban environments, peers may be important models of behaviour. Food choices and consumption may be one way that young migrants adapt to new environments, develop social bonds and fit in with their peers.

A second, complementary explanation is that spending time with peers may facilitate access to and the consumption of these products. Rural-to-urban migrants may learn how, where and what to purchase from their urban-savvy peers. Moreover, peers may educate migrants about their new environments indirectly as they discuss preferred products, thus alerting migrants to these items and encouraging their consumption. Other examples of how social networks encourage new health behaviours exist: novel contraceptive ideals may be transmitted during mundane activities (e.g. gossiping at the market) within informal social networks ${ }^{(46)}$.

Overall, our findings provide evidence connecting urbanization to the consumption of a greater diversity of sugary and fatty foods. Declines in physical activity also contribute to the nutrition transition, and complementary qualitative findings provide evidence for the decline in physical activity and the increase in body fat. As part of the HYTS, the first author conducted semi-structured interviews with selected respondents. Although they were not asked specifically about changes in activity levels, their responses support other aspects of the nutrition transition.

When migrant youth were asked to describe how life in their new urban location differed from life in the countryside, responses describing reduced physical activity were common. Some examples included transportation changes: 'I don't walk far to go to school anymore' and 'People don't walk; they take vehicles'. They also highlighted the reduction in physical labour: 'Now we get water from a pipe'.

Non-migrant youth observed similar changes among their migrant peers. During interviews, non-migrants were asked to describe the changes they observed among migrants who had returned home for vacation. One 12-year-old girl explained how her older, migrant siblings no longer walked anywhere:

Interviewer: "When your brothers and sisters went to Port-au-Prince to live, and then came back on vacation, do you think they changed?'

Respondent: 'Yes.'

Interviewer: 'How so?' 
Respondent: 'They used to walk places. Now they don't walk anymore.'

Interviewer: 'Why do you think that is?'

Respondent: 'Maybe it is because they don't ever walk in the city.'

Another non-migrant 17-year-old girl explained that returned migrants were fatter:

Respondent: 'People who go to live in Port-auPrince get big.'

Interviewer: 'When you say big, do you mean their bodies? Are you talking about their bodies getting fat or the size of their heads [arrogance]?'

Respondent: 'Yes, their bodies.'

Interviewer: 'So people who come back from Portau-Prince, they are fat?'

Respondent: 'Yes. It isn't like it's everyone. But there are a lot of people who get fat bodies. They live without things that cause their hearts to jump out of their chests. They are at ease. They get fat. But it isn't everyone.'

These complementary qualitative findings suggest that the nutrition transition may also operate through an increase in sedentary lifestyles among rural-to-urban migrants and the consequences are observed through increases in body fat.

\section{Limitations and future research}

Despite the contributions of the current study, it suffers from limitations. Migrants and non-migrants may differ from one another on unobserved characteristics related to migration itself and HSBFS consumption that we are unable to control for in our study. Such differences may mean that migrants consumed a wider diversity of HSBFS products at baseline; however, the lack of baseline food consumption data prevents the analysis of these differences. Importantly, the design of the study reduces heterogeneity among respondents by selecting a relatively homogeneous population of youth from the same rural villages who completed primary school together.

Additionally, food categories were limited to popularly consumed food and dichotomous responses without assessing the quantity consumed. This limited our ability to distinguish among individuals who consumed either large or small amounts of HSBFS. However, we judged this method to be most effective given that respondents were unfamiliar with food recall surveys and would likely be unable to respond to more detailed recall methods.

Our findings may also suffer from respondents' bias towards socially favourable 'yes' responses. Although this may lead to incorrect conclusions about the overall consumption levels, it is less of a threat to the ability to differentiate between the eating habits of migrants and non-migrants. Moreover, any bias towards yes responses likely reflects favourable attitudes towards the product and a desire to consume it if given the opportunity.

The study is also limited by its short time horizon; the vast majority migrated to start the school year in October, five months prior to when food diversity was measured. Thus, we are unable to draw conclusions about the lasting effects of these dietary changes. Future studies should consider whether the observed changes in dietary consumption lead to changes in weight status or the development of other related health conditions.

The present study opens the door for future work that unravels how peer social engagement encourages higher HSBFS diversity and consumption. We propose two potential mechanisms by which peer social engagement and consumption are related: (i) that youth migrants adapt new patterns to fit into their new environment; and (ii) that peers indirectly encourage diversity of HSBFS consumption. The role of each factor could be examined by questions that ask about how youth access these items (i.e. purchase for themselves, friends share with them) and examine their attitudes towards peers who consume these specific items. Further work to unravel these processes may reveal strategies for promoting healthier food choices among youth.

\section{Conclusion}

By comparing rural-to-urban youth migrants with rural non-migrants, the present study offers a unique contribution to the current literature on the nutrition transition. Whereas previous research has concluded that ruralto-urban migrants within the Global South consume more fatty and sugary foods, we conclude that adolescent migrants eat a wider diversity of these foods than their non-migrant peers. We also expand previous literature by highlighting how migrant youth's engagement with their new peers may facilitate HSBFS consumption as they adapt to the urban environment.

Our findings should be considered with respect to migrant youth's individual health trajectories. High HSBFS consumption is associated with overweight and developing morbidities that include hypertension, diabetes and CVD. Our findings imply that migrant youth in urban areas consume a wider diversity of HSBFS and may develop strong preferences for these products. In turn, they may also increase the quantity of HSBFS they consume and eventually be at risk of developing degenerative health conditions.

\section{Acknowledgements}

Acknowledgements: Professor Melissa Hardy provided constructive feedback on an earlier draft of the paper. 
Financial support: Data collection was supported by grants to J.H. from the Africana Research Center at the Pennsylvania State University, the Center for Global Studies at the Pennsylvania State University and the National Science Foundation Graduate Research Fellowship Program (grant number DGE-0750756). S.B. received support from the William and Flora Hewlett Foundation (grant number 2012-7598), and all authors benefited from an institutional grant from the National Institute of Child Health and Human Development to the Population Research Institute at Pennsylvania State University (grant number R24 HD041025). The funders had no role in the design, analysis or writing of this article. Conflict of interest: None. Authorship: The authors shared in the conceptualization of the paper, which drew on J.H.'s knowledge of youth migration and Haiti, S.B.'s knowledge of the nutrition transition in the Global South and C.A.'s knowledge of the migrationnutrition interface. J.H. designed and implemented data collection and wrote the initial draft of the background, methods and discussion; S.B. conducted the analyses and wrote the results section; C.A. contributed significantly to the theoretical framework, introduction and discussion. All authors have read and approved the final version of the manuscript. Ethics of buman subject participation: The study was approved by the Institutional Review Board of the Pennsylvania State University.

\section{References}

1. Kain J, Vio F \& Albala C (2003) Obesity trends and determinant factors in Latin America. Cad Saude Publica 19 Suppl. 1, S77-S86.

2. Popkin BM (1999) Urbanization, lifestyle changes and the nutrition transition. World Dev 27, 1905-1916.

3. Popkin BM \& Gordon-Larsen P (2004) The nutrition transition: worldwide obesity dynamics and their determinants. Int J Obes Relat Metab Disord 28, Suppl. 3, S2-S9.

4. Popkin BM (1994) The nutrition transition in low-income countries: an emerging crisis. Nutr Rev 52, 285-298.

5. Kojima R (1996) Population migration and urbanization in developing countries. Dev Econ 34, 349-369.

6. Wang Y \& Lobstein T (2006) Worldwide trends in childhood overweight and obesity. Int J Pediatr Obes 1, 11-25.

7. Cayemittes M, Placide MF, Mariko S et al. (2007) Enquête Mortalité, Morbidité et Utilisation des Services, Haïti, 2005-2006. Calverton, MD: Ministère de la Santé Publique et de la Population, Institut Haitien de l'Enfance and Macro International Inc.

8. Cayemittes M, Basangu MF, Bizimana J de D et al. (2013) Enquête Mortalité, Morbidité et Utilisation des Services, Haïti, 2012. Calverton, MD: Ministère de la Santé Publique et de la Population, Institut Haïtien de l'Enfance and ICF International.

9. Jean-Baptiste E, Larco P, Charles-Larco N et al. (2006) Glucose intolerance and other cardiovascular risk factors in Haiti (PREDIAH). Diabetes Metab 32, 443-451.

10. Lutter CK, Chaparro CM \& Munoz S (2011) Progress towards Millennium Development Goal 1 in Latin America and the Caribbean: the importance of the choice of indicator for undernutrition. Bull World Health Organ 89, 22-30.

11. Harpham T (2009) Urban health in developing countries: what do we know and where do we go? Health Place 15 , 107-116.
12. Creber RMM, Smeeth L, Gilman RH et al. (2010) Physical activity and cardiovascular risk factors among rural and urban groups and rural-to-urban migrants in Peru: a crosssectional study. Rev Panam Salud Publica 28, 1-8.

13. Popkin BM (1993) Nutritional patterns and transitions. Popul Dev Rev 19, 138.

14. Mendez M \& Popkin B (2004) Globalization, urbanization and nutritional change in the developing world. In Globalization of Food Systems in Developing Countries: Impact on Food Security and Nutrition. FAO Food and Nutrition Paper no. 83, pp. 55-80. Rome: FAO.

15. Palmer RW (2009) The Caribbean Economy in the Age of Globalization. New York: Macmillan.

16. Hawkes C \& Thow AM (2008) Implications of the Central America-Dominican Republic-Free trade agreement for the nutrition transition in Central America. Rev Panam Salud Publica 24, 345-360.

17. Popkin BM (1980) Time allocation of the mother and child nutrition. Ecol Food Nutr 9, 1-14.

18. Popkin BM \& Bisgrove EZ (1988) Urbanization and nutrition in low-income countries. Food Nutr Bull 10, 3-23.

19. Hawkes C (2006) Uneven dietary development: linking the policies and processes of globalization with the nutrition transition, obesity and diet-related chronic diseases. Global Health 2, 4 .

20. Rivera JA, Barquera S, González-Cossío T et al. (2004) Nutrition transition in Mexico and in other Latin American countries. Nutr Rev 62, 7 Pt 2, S149-S157.

21. Ghassemi H, Harrison G \& Mohammad K (2002) An accelerated nutrition transition in Iran. Public Health Nutr 5, 149-155.

22. Desilets M-C, Rivard M, Shatenstein B et al. (2007) Dietary transition stages based on eating patterns and diet quality among Haitians of Montreal, Canada. Public Health Nutr 10, 454-463.

23. Bansal D, Satija A, Khandpur N et al. (2010) Effects of migration on food consumption patterns in a sample of Indian factory workers and their families. Public Health Nutr 13, 1982-1989.

24. Torun B, Stein AD, Schroeder D et al. (2002) Rural-to-urban migration and cardiovascular disease risk factors in young Guatemalan adults. Int J Epidemiol 31, 218-226.

25. Yaqub S (2009) Child Migrants With and Without Parents: Census-Based Estimates of Scale and Characteristics in Argentina, Chile and South Africa. Florence: UNICEF Innocenti Research Centre.

26. Justesen M \& Verner D (2007) Factors Impacting Youth Development in Haiti. Washington, DC: World Bank Publications.

27. Lunde H (2009) Haiti Youth Survey 2009. vol. I: Tabulation Report. Oslo: Fafo.

28. Blackwell DL, Hayward MD \& Crimmins EM (2001) Does childhood health affect chronic morbidity in later life? SOC Sci Med 52, 1269-1284.

29. Ben-Shlomo Y \& Kuh D (2002) A life course approach to chronic disease epidemiology: conceptual models, empirical challenges and interdisciplinary perspectives. Int J Epidemiol 31, 285-293.

30. Fiorito LM, Marini M, Mitchell DC et al. (2010) Girls' early sweetened carbonated beverage intake predicts different patterns of beverage and nutrient intake across childhood and adolescence. J Am Diet Assoc 110, 543-550.

31. Collins WA \& Steinberg L (2006) Adolescent development in interpersonal context. In Handbook of Child Psychology, 6th ed., vol. 3, pp. 551-592 [W Damon and RM Lerner, editors]. Hoboken, NJ: John Wiley \& Sons, Inc.

32. Smith JM (2001) When the Hands are Many: Community Organization and Social Change in Rural Haiti. Ithaca, NY: Cornell University Press.

33. Contento IR, Williams SS, Michela JL et al. (2006) Understanding the food choice process of adolescents in the context of family and friends. J Adolesc Health 38, 575-582. 
34. Story M, Neumark-Sztainer D \& French S (2002) Individual and environmental influences on adolescent eating behaviors. J Am Diet Assoc 102, 3 Suppl., S40-S51.

35. Bowen L, Ebrahim S, De Stavola B et al. (2011) Dietary intake and rural-urban migration in India: a crosssectional study. PLOS ONE 6, e14822.

36. Ballard T, Coates J, Swindale A et al. (2011) Household Hunger Scale: Indicator Definition and Measurement Guide. Food and Nutrition Technical Assistance II Project, FHI 360. http://www.fantaproject.org/monitoring-and-evaluation/ household-hunger-scale-hhs (accessed November 2013).

37. Rutstein SO \& Johnson K (2004) The DHS Wealth Index. Calverton, MD: ORC Macro.

38. Rubin DB (1987) Multiple Imputation for Nonresponse in Surveys. New York: John Wiley \& Sons.

39. Krus DJ \& Wilkinson SM (1986) Demonstration of properties of a suppressor variable. Behav Res Meth Instrum Comput 18, 21-24.

40. Mendez MA \& Popkin BM (2004) Globalization, urbanization and nutritional change in the developing world. $e-J A D E$ 1, 220-241.
41. Harrison A, Smit J, Hoffman S et al. (2012) Gender, peer and partner influences on adolescent HIV risk in rural South Africa. Sex Health 9, 178-186.

42. Viner RM, Ozer EM, Denny S et al. (2012) Adolescence and the social determinants of health. Lancet 379 , $1641-1652$.

43. Salvy S-J, de la Haye K, Bowker JC et al. (2012) Influence of peers and friends on children's and adolescents' eating and activity behaviors. Physiol Behav 106, 369-378.

44. Karimi-Shahanjarini A, Omidvar N, Bazargan M et al. (2010) Iranian female adolescent's views on unhealthy snacks consumption: a qualitative study. Iran J Public Health 39, 92-101; available at http://journals.tums.ac. ir/abs.aspx? org_id=59\&culture_var =en\&journal_id=5\&issue_id= 1951 \&manuscript_id $=16699 \&$ segment $=$ en

45. Wouters EJ, Larsen JK, Kremers SP et al. (2010) Peer influence on snacking behavior in adolescence. Appetite $\mathbf{5 5}$, $11-17$.

46. Bongaarts J \& Watkins SC (1996) Social interactions and contemporary fertility transitions. Popul Dev Rev 22, 639. 